Article

\title{
Surface Modification of Carbon Fibers by Grafting PEEK-NH2 for Improving Interfacial Adhesion with Polyetheretherketone
}

\author{
Elwathig. A. M. Hassan 1,2,3,4® , Tienah. H.H. Elagib ${ }^{1}$, Hafeezullah Memon ${ }^{2,5}{ }^{\circledR}$, Muhuo Yu ${ }^{1,2,3}$ \\ and Shu Zhu 1,2,3,* \\ 1 Key Laboratory of High-Performance Fibers \& Products, Ministry of Education, College of Materials Science \\ and Engineering, Donghua University, Shanghai 200051, China; elwathig2011@uofg.edu.sd (E.A.M.H.); \\ solarahussain@yahoo.com (T.H.H.E.); yumuhuo@dhu.edu.cn (M.Y.) \\ 2 Key Laboratory of Shanghai City for lightweight composites, Donghua University Center for Civil Aviation \\ Composites, Donghua University, Shanghai 200051,China; hafeezullah_m@yahoo.com \\ 3 State Key Laboratory for Modification of Chemical Fibers and Polymer Materials, Donghua University, \\ Shanghai 200051, China \\ 4 Industries Engineering and Technology, University of Gezira, Wad Madani 21111, Sudan \\ 5 Key Laboratory of Textile Science \& Technology, Ministry of Education, College of Textiles, \\ Donghua University, 2999 North Renmin Road, Shanghai 201620, China \\ * Correspondence: zhushu@dhu.edu.cn; Tel.: +86-21-67874266
}

Received: 19 February 2019; Accepted: 1 March 2019; Published: 7 March 2019

check for updates

\begin{abstract}
Due to the non-polar nature and low wettability of carbon fibers (CFs), the interfacial adhesion between CFs and the polyetheretherketone (PEEK) matrix is poor, and this has negative effects on the mechanical properties of CF/PEEK composites. In this work, we established a modification method to improve the interface between CFs and PEEK based chemical grafting of aminated polyetheretherketone (PEEK-NH${ }_{2}$ ) on $\mathrm{CFs}$ to create an interfacial layer which has competency with the PEEK matrix. The changed chemical composition, surface morphology, surface energy, and interlaminar shear strength were investigated. After grafting, the interlaminar shear strength (ILSS) was improved by $33.4 \%$ due to the covalent bonds in the interface region, as well as having good compatibility between the interface modifier and PEEK. Finally, Dynamic Mechanical Analysis (DMA) and Scanning Electron Microscopy (SEM) observation also confirmed that the properties of the modified CF/PEEK composites interface were enhanced. This work is, therefore, a beneficial approach towards enhancing the mechanical properties of thermoplastic composites by controlling the interface between CFs and the PEEK matrix.
\end{abstract}

Keywords: carbon fiber (CF); polyetheretherketone (PEEK); aminated polyetheretherketone (PEEK-NH ${ }_{2}$ ); interfacial adhesion

\section{Introduction}

As lightweight materials, carbon fiber/polyetheretherketone (CF/PEEK) composites have been used in a broad range of applications with a promising future in automobiles, aerospace, military defense, biomedicine, and the electronic industry, owing to their low density, high specific strength, and high thermal stability [1-4]. Previous studies have proved that the effective mechanical properties of the composites depend on the properties of each of the components as well as on the fiber/matrix interface quality [5]. However, PEEK exhibits some drawbacks such as poor adhesion of hydrophilic reactive groups in PEEK chains [6,7]. On the other hand, due to its non-polar surface and compound of highly crystallized graphitic basal planes with inert structures, the pristine CFs have poor interaction 
with most of the polymers [8]. For these reasons, their applications have been limited because of weak fiber-matrix adhesion, which causes premature failure of the composites [9], thus, encouraging improvements in their performance for more demanding technological applications. Therefore, varieties of methods regarding surface modifications of CFs were established to improve the interfacial adhesion of composites, such as oxidation treatment, plasma, and ozone treatment [10-15]. However, most of them were established for improving interfacial adhesion between CFs and thermosetting polymers because of strong chemical interactions between modified CFs and thermosetting polymers. In the case of thermoplastic polymers, it is difficult for the functional groups provided by thermoplastics to react chemically with the surface functional groups of CFs. Therefore, only a little improvement can be achieved by increasing surface roughness or interacting with oxygen-containing functional groups. A polymer as compatibilizer that has a similar, or the same main component as the matrix, is desired to promote interfacial adhesion of the composites [16]. Grafting of the compatibilizer of the modified PEEK creates a strong interface layer on CFs, which improves interfacial adhesion between fiber and the matrix by way of a "bridging" effect. The compatibilizer either interacts physically or chemically with the fiber surface or has an excellent compatibility with the polymer matrix. Yuan et al. [17] applied polyethersulfone (PES) emulsion sizing to the CF surface, and the interfacial strength of CF/PES composites was successfully increased by $26 \%$. Liu et al. [18] improved interfacial adhesion of $\mathrm{CF} /$ poly(phthalazinoneether ketone) (PPEK) by coating it in a PPEK film. Based on the discussions above, it can be maintained that grafting matrix-compatible resin on the CF surface may produce a synergistic effect on improving the interfacial properties of composites.

In this study, low contents of PEEK with plentiful amine groups on its molecular chains were chosen as the modifiers and were grafted onto CFs by covalent linkage. It is expected that those physical and chemical bonds, as well as molecular chain entanglement between modified PEEK and the PEEK matrix, are beneficial to the improvement of interfacial interactions.

\section{Materials and Methods}

\subsection{Materials}

CF fabrics (3K-T300-plain) were provided by Toray Industries, Inc. (Tokyo, Japan). PEEK (1000-300G) was supplied in film form by Victrex (Lancashire, UK). Acetone ( $\geq 99.5 \%)$ was received from Shanghai Yunli Economic and Trading Co., Ltd. (Shanghai, China). Dimethylacetamide (DMA) was provided from Shanghai Ling Feng Chemical Reagent Co., Ltd. (Shanghai, China).

\subsection{Amination of PEEK}

A stirred suspension of PEEK in $\mathrm{HNO}_{3} / \mathrm{H}_{2} \mathrm{SO}_{4}$ was heated under the conditions specified in Table 1. The product $\left(\mathrm{PEEK}-\mathrm{NO}_{2}\right)$ was filtered and washed with water until $\mathrm{pH} 7$ was obtained, then it was washed with ethanol, acetone and dried in an oven at $80{ }^{\circ} \mathrm{C} . \mathrm{SnCl}_{2}$ was dissolved in $\mathrm{HCl}$ solution $(37 \%)$ and then ethanol $(50 \mathrm{~mL})$ was added into the mixture. After stirring at $65{ }^{\circ} \mathrm{C}$ for $15 \mathrm{~min}$, the prepared PEEK-NO 2 powder was slowly poured in and the reaction was kept for $4 \mathrm{~h}$ at $65^{\circ} \mathrm{C}$. Then the yellowish precipitate was filtered off and washed with distilled water. Followed by drying in an oven for $24 \mathrm{~h}$, yellowish PEEK-NH $\mathrm{N}_{2}$ was prepared (Figure 1).

Table 1. Conditions of the nitration reaction of the products.

\begin{tabular}{|c|c|c|}
\hline Batch & $\mathrm{T} /\left({ }^{\circ} \mathrm{C}\right)$ & Reaction Time/(min) \\
\hline${\mathrm{PEEK}-\mathrm{NH}_{2}-1}$ & 50 & 30 \\
\hline PEEK-NH ${ }_{2}-2$ & 50 & 60 \\
\hline PEEK-NH ${ }_{2}-3$ & 50 & 90 \\
\hline $\mathrm{PEEK}^{-\mathrm{NH}_{2}-4}$ & 50 & 120 \\
\hline
\end{tabular}




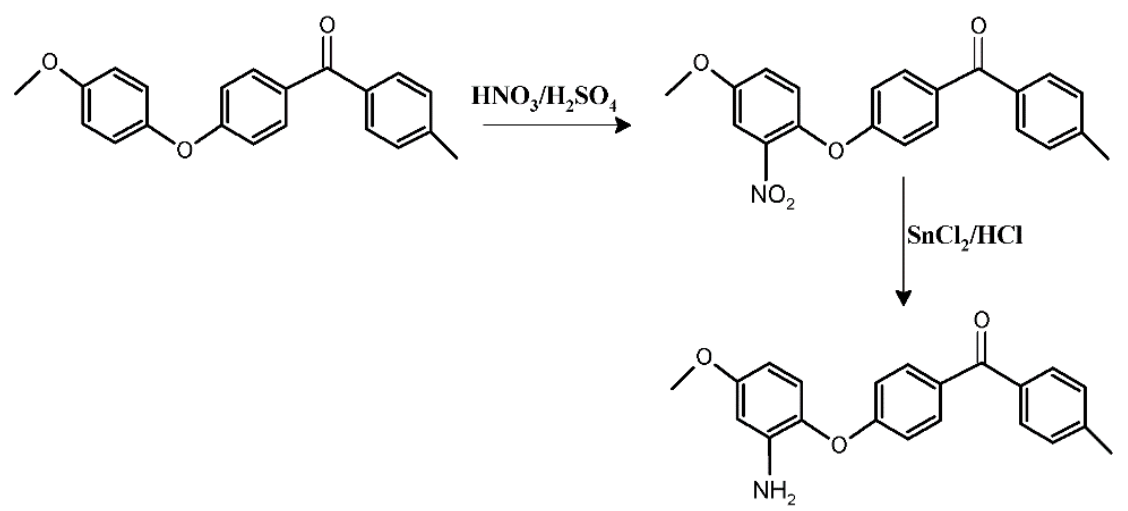

Figure 1. Amination of polyetheretherketone (PEEK).

\subsection{Grafting PEEK-NH2 onto CFS}

The $\mathrm{CFs}$ were refluxed in acetone for $48 \mathrm{~h}$ at $70{ }^{\circ} \mathrm{C}$ to remove sizing agents, then they were washed repeatedly in deionized water and dried at $80^{\circ} \mathrm{C}$ to obtain the desized CF. Subsequently, the CFs were treated with Meldrum acid solution at $30^{\circ} \mathrm{C}$ for $3 \mathrm{~h}$ followed by washing with acetone and drying. The obtained CFs were denoted as activated-CFs (ACFs). The activated CFs were tied to a glass frame and placed into PEEK- $\mathrm{NH}_{2}$ / dimethylformamide (DMF) solution with a different degree of amination, then the reaction was performed under nitrogen atmosphere at $50{ }^{\circ} \mathrm{C}$ for $48 \mathrm{~h}$ to induce plenty of PEEK-NH $\mathrm{N}_{2}$ onto the $\mathrm{CF}$ surface. The samples were denoted as PEEK-NH $\mathrm{NH}_{2}-1 @ \mathrm{CF}, \mathrm{PEEK}-\mathrm{NH}_{2}-2 @ \mathrm{CF}$, PEEK-NH ${ }_{2}-3 @ C F$, and PEEK-NH ${ }_{2}-4 @ C F$. The overall reaction is shown in Figure 2.

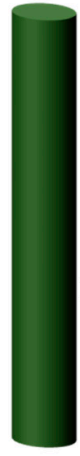

Desized-CF

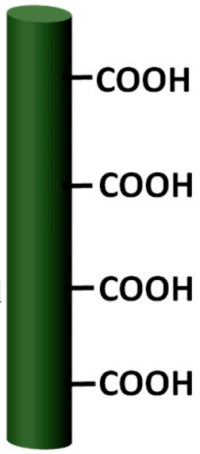

Activated CF

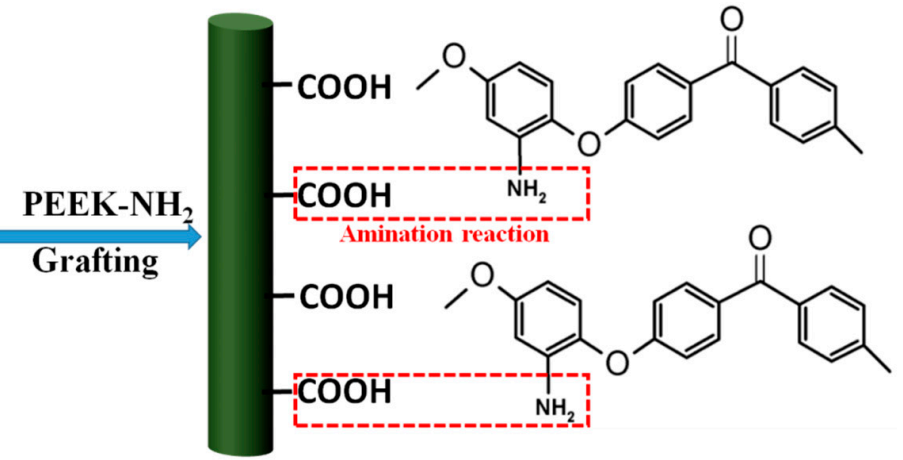

PEEK-NH ${ }_{2}$ grafted $\mathrm{CF}$

Figure 2. Complete representation of the grafting procedures.

\subsection{Preparation of Modified CF/PEEK Resin Composites}

The desized, modified CF and PEEK films were dried in a vacuum oven at $100{ }^{\circ} \mathrm{C}$ for $24 \mathrm{~h}$ before the manufacturing procedures of composites took place. The laminates were manufactured by alternatively placing 8 plies of $C F$ fabrics and 9 plies of PEEK films with the transverse dimensions of $200 \mathrm{~mm} \times 150 \mathrm{~mm}$. The compression molding method was used to prepare CF/PEEK composite panels at $390{ }^{\circ} \mathrm{C}$ under the pressure of $2.5 \mathrm{MPa}$ for $25 \mathrm{~min}$. Finally, the laminates were cooled to $100{ }^{\circ} \mathrm{C}$ with a cooling rate of $5{ }^{\circ} \mathrm{C} / \mathrm{min}$ by keeping a constant pressure $(2.5 \mathrm{MPa})$. The laminates had a matrix volume fraction of $60 \%$, a fiber volume fraction of $40 \%$, and an average void content $<2.5 \%$.

\section{Characterizations}

Morphologies of modified CF and fractural morphologies of CF/PEEK composites were observed using a scanning electron microscope (SEM) (HITACHI S-300N, Tokyo, Japan) with an acceleration voltage of 15-18 kV. Solid-state NMR experiments were performed on a Bruker DMX-400 spectrometer operating at a ${ }^{13} \mathrm{C}$ frequency of $100.62 \mathrm{MHz}$. The functional groups of modified PEEK and PEEK grafted 
CFs were identified by a Fourier transform infrared (FT-IR) spectrometer (Nicolet 8700, USA) using powder-pressed $\mathrm{KBr}$ disks in wave numbers ranging from $400 \mathrm{~cm}^{-1}$ to $4000 \mathrm{~cm}^{-1}$. Thermogravimetric analysis (TGA) was performed under air atmosphere using a TGA Q5000 IR (TA Instruments-Waters LLC, New Castle, DE, USA) with a heating rate of $10{ }^{\circ} \mathrm{C} / \mathrm{min}$ from room temperature to $800{ }^{\circ} \mathrm{C}$. The contact angle analysis test (OCA40Micro, Germany) was used to determine the surface energies of modified CF and the polar components of surface energies were calculated according to the Wilhelmy method [19]. Five measurements were performed at different locations for each kind of CF.

Dynamic mechanical analysis (DMA) was carried out using a dynamic mechanical thermal analyzer (TA Q800, New Castle, DE, USA) under a three-point bending mode. The samples were tested at a frequency of $1.0 \mathrm{~Hz}$ from $30{ }^{\circ} \mathrm{C}$ to $290^{\circ} \mathrm{C}$, at a heating rate of $10^{\circ} \mathrm{C} / \mathrm{min}$. Interlaminar shear strength (ILSS) of composites were carried out on a universal testing machine (LABSANS LD26.105, China) according to ASTM D7264. Five parallel measurements were conducted and averaged for each final result. The standard deviation was indicated by error bars.

\section{Results and Discussion}

\subsection{Surface Morphologies of Modified CFs}

As shown in Figure 3, PEEK- $\mathrm{NH}_{2}$ were distributed on the CF surface, and the amount of amine-PEEK depended on the degree of amination, confirming that the grafting of PEEK- $\mathrm{NH}_{2}$ increases with the increasing degree of amination. For PEEK- $\mathrm{NH}_{2}-4 @ \mathrm{CF}$, the fiber uniformly wrapped by particles of PEEK (illustrated by arrows) indicated that PEEK- $\mathrm{NH}_{2}$ was chemically grafted onto CFs. It can be seen in Figure 3D, that a layer of uniform PEEK particles on the fiber surface was generated, which served as a bridge to connect $\mathrm{CF}$ and the PEEK matrix at the composite interface region, and consequently enhanced the interfacial adhesion between $\mathrm{CFs}$ and the matrix.

A

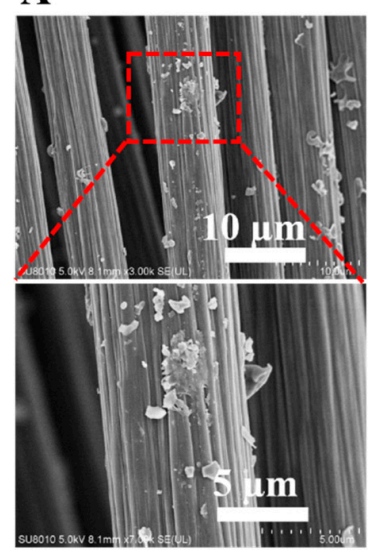

B

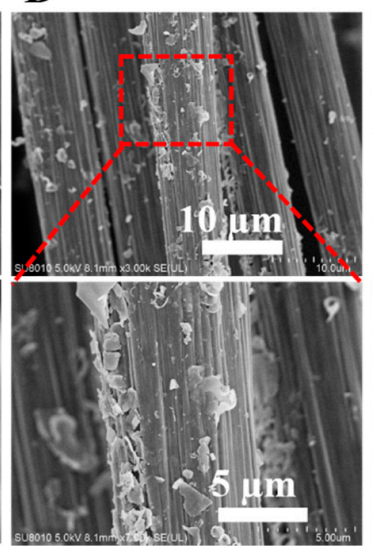

C

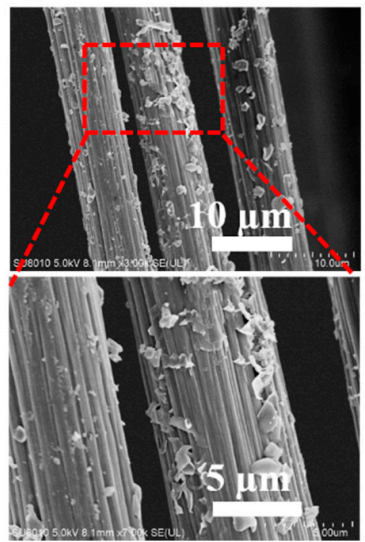

D

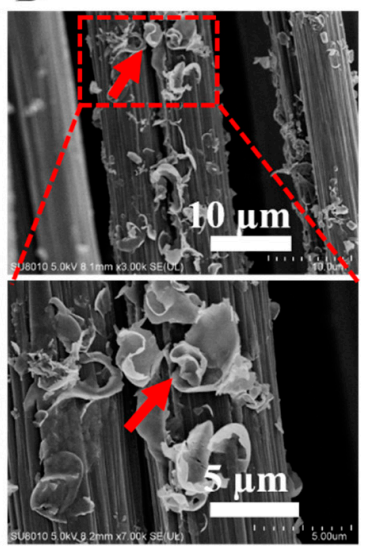

Figure 3. SEM images of (A) PEEK-NH $2-1 @ C F,(B) P E E K-N_{2}-2 @ C F,(C) P E E K-N_{2}-3 @ C F$, and (D) PEEK-NH$-4 @$ CF.

\subsection{Surface Energies of Modified CFs}

Polar liquid (water) and non-polar liquid (glycerol) was used to determine the dispersive $\left(\gamma^{\mathrm{d}}\right)$ and polar $\left(\gamma^{\mathrm{P}}\right)$ components of surface energy according to the Wilhelmy method [19]. Surface polar functional groups of CFs enhanced the polar component, while the topography of fiber dominated the dispersive component. Therefore, the enhanced polar component of surface energy can be interpreted as many polar amino groups induced onto the surface of grafted CFs. It was found that an increase in total surface energy and its polar component appears to be due to the increase in the percentage of surface polar functional groups $\left(\mathrm{NH}_{2}\right)$. In fact, an approximate linear relationship can be obtained between the polar component of the surface energy, and polar functional groups on the surface of CFs (see Table 2). The improved dispersive component of different CF surfaces can be ascribed to 
increased fiber surface roughness caused by the polymer sizing agent containing PEEK- $\mathrm{NH}_{2}$ which was grafted on the fiber surface. The improvement of carbon fiber surface energy effectively improved the interfacial bonding between fiber and polymer matrices.

Table 2. Surface energies of modified carbon fibers (CFs).

\begin{tabular}{|c|c|c|c|c|c|}
\hline \multirow{2}{*}{ Samples } & \multicolumn{2}{|c|}{ Contact Angle $\left({ }^{\circ}\right)$} & \multirow{2}{*}{$\gamma^{\mathrm{d}}\left(\mathrm{mJm}^{-2}\right)$} & \multirow{2}{*}{$\gamma^{\mathrm{p}}\left(\mathrm{mJm} \mathrm{m}^{-2}\right)$} & \multirow{2}{*}{$\gamma\left(\mathrm{mJm}^{-2}\right)$} \\
\hline & Water & Glycerol & & & \\
\hline Desized-CF & 79.9 & 92.4 & 1.03 & 44.64 & 45.67 \\
\hline PEEK-NH ${ }_{2}-1 @ C F$ & 77 & 81 & 1.50 & 64.92 & 66.42 \\
\hline PEEK-NH ${ }_{2}-2 @ C F$ & 74 & 78.2 & 1.62 & 70.48 & 72.10 \\
\hline PEEK-NH ${ }_{2}-3 @ C F$ & 71 & 75.2 & 1.92 & 77.52 & 79.44 \\
\hline PEEK-NH $2-4 @ C F$ & 68 & 73 & 1.67 & 79.71 & 81.38 \\
\hline
\end{tabular}

\subsection{Thermal Stability of Modified CFs}

As shown in Figure 4, the initial degradation temperature of desized@CF was about $640{ }^{\circ} \mathrm{C}$ [20]. Meanwhile, there was a significant weight loss for CF grafted with PEEK-NH $\mathrm{N}_{2}$ which showed two distinct weight losses at $480^{\circ} \mathrm{C}$ and $640{ }^{\circ} \mathrm{C}$. It can be seen that with increasing amination degree the thermal degradation continuously increased which was attributed to reactions with the main chain and derivatives of the amino group. This could have affected the level of the improvement, especially at high processing temperature. The results of the thermal analysis for all investigated samples are summarized in Table 3. It is well-known that the amino group of PEEK can form interaction bonds with basic groups in PEEK, thus, leading to the stabilization of the aromatic of the amino group to some extent.

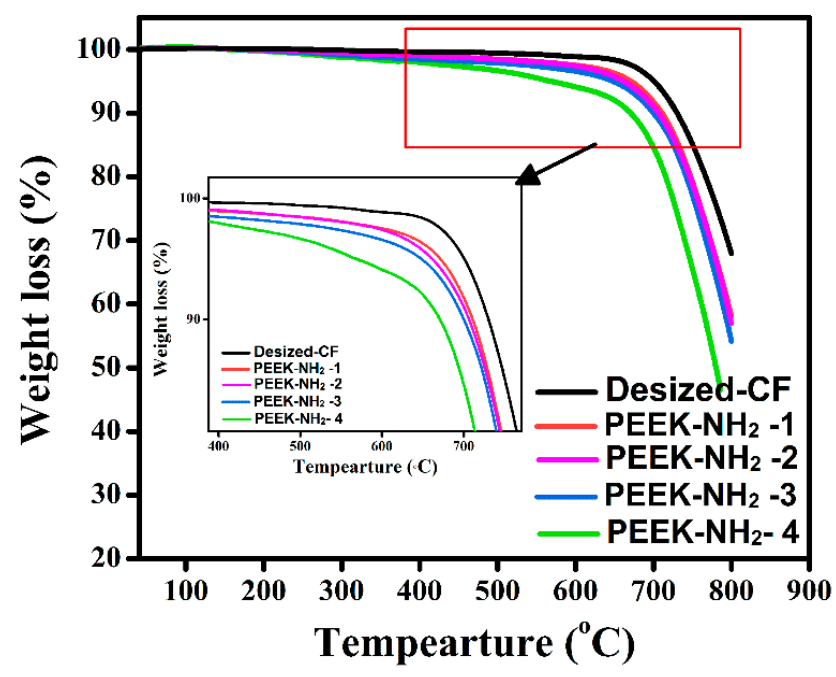

Figure 4. Thermogravimetric analysis (TGA) of different degrees of amination of PEEK.

Table 3. Thermal properties of modified CFs grafted with PEEK-NH

\begin{tabular}{|c|c|c|}
\hline Sample & $\mathrm{T}_{5}\left({ }^{\circ} \mathrm{C}\right)$ & Char Yield (\%) \\
\hline Desized-CF & 700 & 68 \\
\hline${\mathrm{PEEK}-\mathrm{NH}_{2}-1 @ \mathrm{CF}}$ & 674 & 59 \\
\hline PEEK-NH $\mathrm{N}_{2}-2 @ \mathrm{CF}$ & 670 & 57 \\
\hline PEEK-NH $2-3 @ C F$ & 647 & 54 \\
\hline PEEK-NH $_{2}-4 @ C F$ & 568 & 46 \\
\hline
\end{tabular}

$\mathrm{T}_{5}$ : Temperature at $5 \%$ weight loss in air. Char yield (\%): Residual weight at $\sim 800{ }^{\circ} \mathrm{C}$ in air. 


\subsection{The Surface Chemical Elemental Composition of CFs}

\subsubsection{NMR of Modified PEEK}

The reaction of the functional polymer with $-\mathrm{NO}_{2}$ was investigated with NMR. The ${ }^{13} \mathrm{C}$ NMR spectrum of PEEK and PEEK-NO $\mathrm{NO}_{2}$ are given in Figure 5. The polymer backbone of PEEK peaks resonated at 120.2, 132.5, 150.8, 160, and 193 ppm. These peaks shifted to lower chemical shifts in the functional polymer (PEEK-NO $\mathrm{N}_{2}$ ) compared with that of PEEK, and a new peak at $142.4 \mathrm{ppm}$ was observed, which was attributed to the $-\mathrm{NO}_{2}$ grafted onto the PEEK main chain [21].

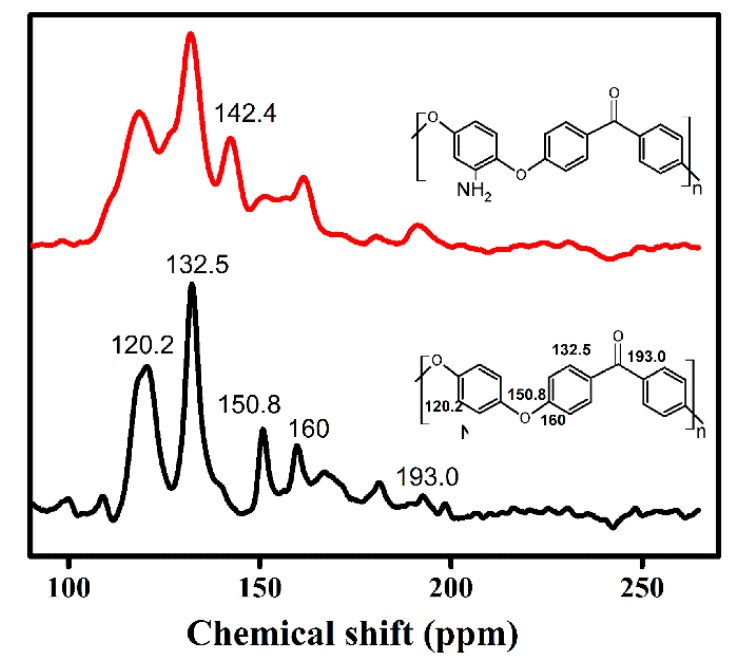

Figure 5. ${ }^{13} \mathrm{C}$ NMR of PEEK and PEEK-NO ${ }_{2}$.

\subsubsection{FTIR Analysis of Modified PEEK}

Figure 6A shows the infrared spectra for PEEK and nitrated PEEK with different nitration degrees, and the absorption bands observed at $1543 \mathrm{~cm}^{-1}$, and $1346 \mathrm{~cm}^{-1}$ relate to the unsymmetrical and symmetrical stretching of the nitro group, respectively [21]. The appearance of a band at $3434 \mathrm{~cm}^{-1}$ related to $\mathrm{N}-\mathrm{H}$ stretching, which increased with the increasing degree of nitration, and the peaks at $928 \mathrm{~cm}^{-1}$ were assigned to $\mathrm{C}-\mathrm{N}$ stretching. For PEEK-NH $\mathrm{N}_{2}$, as shown in Figure $6 \mathrm{~B}$, the peaks at $3474 \mathrm{~cm}^{-1}, 3374 \mathrm{~cm}^{-1}$, and $1651 \mathrm{~cm}^{-1}$ were attributed to $\mathrm{N}-\mathrm{H}$ stretching, the peak at $1306.3 \mathrm{~cm}^{-1}$ was attributed to $\mathrm{C}-\mathrm{N}$ stretching, and the peak at $1534 \mathrm{~cm}^{-1}$ was attributed to $\mathrm{N}=\mathrm{N}$ stretching and the intensity of this group increased with amination degree increases [22]. All these changes indicated that the nitro groups were reduced to amino groups. For activated CFs (Figure 6C), peaks observed at $3439 \mathrm{~cm}^{-1}, 1753 \mathrm{~cm}^{-1}$, and $1118 \mathrm{~cm}^{-1}$ were associated with stretching vibrations of $-\mathrm{OH}$ groups, $\mathrm{C}=\mathrm{O}$ groups, and $-\mathrm{COOH}$ groups, respectively. For the PEEK- $\mathrm{NH}_{2}$ grafted $\mathrm{CFs}$, the disappearance of the peak located at $1710 \mathrm{~cm}^{-1}$ verified the alteration of the molecular structure of the carboxylic acid group [23]. The peak at $1531 \mathrm{~cm}^{-1}$ corresponded to the bending vibration of the $\mathrm{N}-\mathrm{H}$ of amide, indicating that PEEK- $\mathrm{NH}_{2}$ was grafted onto the fiber surface through covalent bonds [24]. 
A

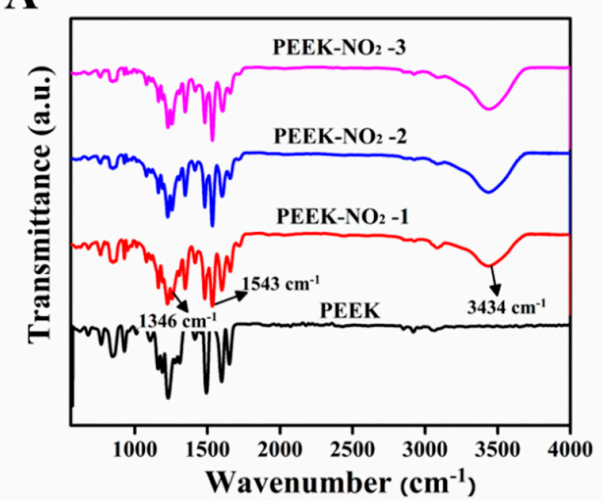

B

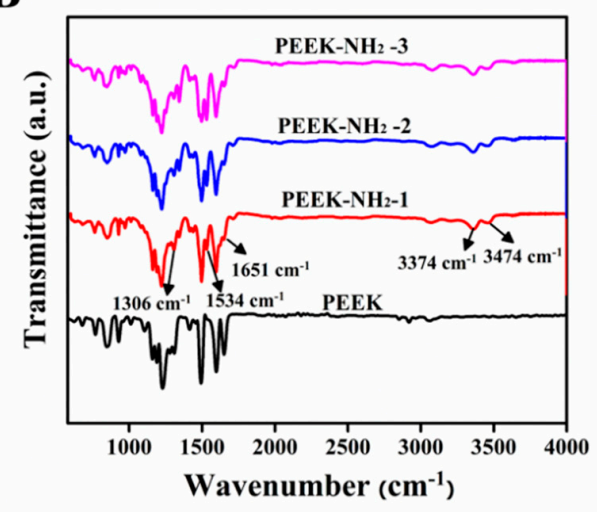

C

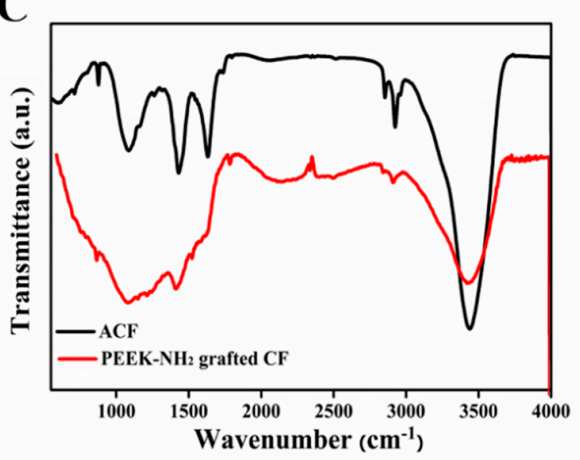

Figure 6. FTIR spectra (A) nitrided PEEK, (B) aminated PEEK, and (C) activated-CF (ACF) and PEEK-NH $\mathrm{N}_{2}$ grafted $\mathrm{CF}$.

\subsection{Mechanical Properties of Modified CFs}

The typical stress-strain curves obtained from the ILSS tests of modified CF/PEEK composites are presented in Figure 7A. There was a slight increase in the maximum load of the ILSS test with the increasing amination degree of the modifier, and then it decreased when the amination degree was further increased. The inset of Figure 7A shows the morphologies of failure modes observed in the CF/PEEK laminates after ILSS tests were carried out. The fracture surfaces of specimen after ILSS tests were delamination cracked, and located at the critical ply interface. ILSS of CF/PEEK composites modified by PEEK- $\mathrm{NH}_{2}$ increased compared with that of the desized@CF composite as shown in Figure 7B. The results suggest that the compatibilizer PEEK- $\mathrm{NH}_{2}$ influenced the mechanical properties of $\mathrm{CF} / \mathrm{PEEK}$. For PEEK-NH $\mathrm{N}_{2}-1 @ \mathrm{CF}$ and PEEK-NH $\mathrm{N}_{2}-2 @ \mathrm{CF}$, the amino groups were not enough to be attached uniformly onto the CF surface, thus, the fiber surface was not totally covered by the grafting material. Hence, ILSS showed only a slight improvement. For PEEK-NH $-3 @ C F$, there were enough active groups (e.g., $\mathrm{NH}_{2}$ ) in the PEEK. Therefore, the amino of PEEK- $\mathrm{NH}_{2}$ also had the chemical reaction and intermolecular force of $\mathrm{COOH}$ groups of activated $\mathrm{CFs}$, and thus, gave uniform polymer grafting. Hence, improvement in ILSS for PEEK-NH $\mathrm{N}_{2}-3 @ C F$ reached a maximum, i.e., $33.4 \%$. In addition, the molecular backbone of PEEK- $\mathrm{NH}_{2}$ was similar to that of PEEK. Thus, PEEK and PEEK- $\mathrm{NH}_{2}$ could have good physical compatibility. These results demonstrated a significantly higher level of improvements than were reported in previous studies $[15,25,26]$. But compared with our previous study [2], there was a limited level of improvement, which could be attributed to the sensitivity of the amino group to high temperatures. On the other hand, when increasing the amination degree, as in PEEK-NH $\mathrm{N}_{2}-4 @ \mathrm{CF}$, the ILSS tended to decrease due to lower thermal stability. Because of the lower degradation temperature (Figure 4), the interfacial layer of this sample might have quickly degraded and formed a weak interfacial layer during the processing of CF/PEEK composites at high temperatures. 
A

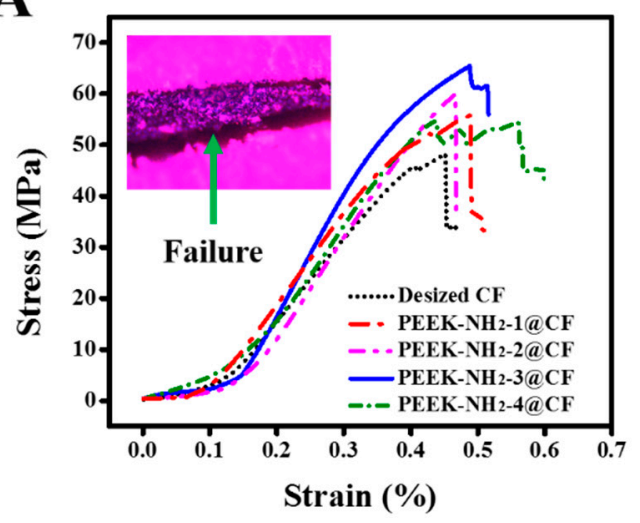

B

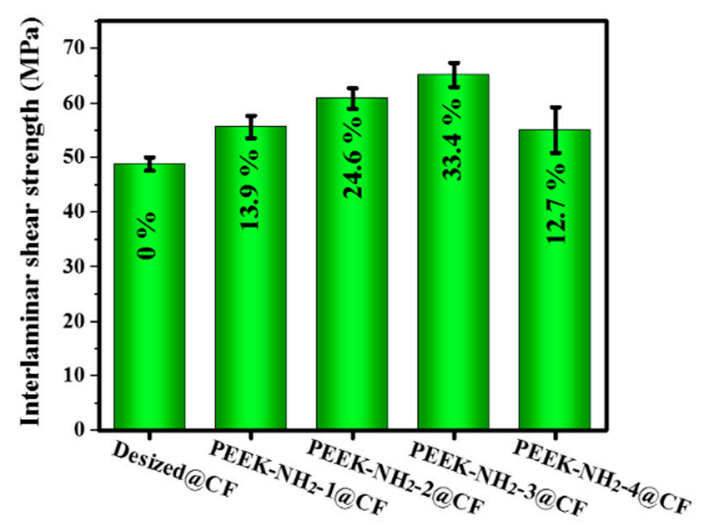

Figure 7. (A) Stress-strain curves in interlaminar shear strength (ILSS) tests, (B) ILSS at different degrees of amination of PEEK.

\subsection{Dynamic Mechanical Analysis of Modified CFs}

The variation in the storage modulus $\left(\mathrm{E}^{\prime}\right)$ as a function of temperature for the $\mathrm{PEEK}-\mathrm{NH}_{2}$ modified composites is given in Figure 8. There was a clear increase in $\mathrm{E}^{\prime}$ after modification of CFs with PEEK-NH $\mathrm{N}_{2}$, and the maximum $\mathrm{E}^{\prime}$ values were found for the PEEK-NH $\mathrm{N}_{2}-3 @ \mathrm{CF}$ composite. This indicates that the CF/PEEK interaction adhesion improved due to the reaction between the amino groups of PEEK, and $\mathrm{COOH}$ groups of $\mathrm{CF}$. That is to say, the compatibilizer PEEK- $\mathrm{NH}_{2}$ was likely to have a good effect on the interfacial adhesion between the PEEK matrix and CFs. However, due to the high processing temperature of $\mathrm{CF} / \mathrm{PEEK}$ composites, $\mathrm{PEEK}-\mathrm{NH}_{2}$ led to more degradation with an increased degree of amination, which was reflected in decreased storage modulus probably due to damage of the interfacial layer in CF/PEEK composites.

The $\tan \delta$ of the composites mainly depended on the interface between fiber and matrix. A good interface bore greater stress and less energy dissipation. However, composite materials with poor interfacial bonding tended to dissipate more energy showing a high magnitude of damping peak in comparison to a material with a strongly bonded interface. This shows that the peak value of $\tan \delta$ in the modified composites with PEEK- $\mathrm{NH}_{2}$ was lower than that of $\mathrm{CF} / \mathrm{PEEK}$ without PEEK-NH $\mathrm{N}_{2}$. It was suggested that the interfacial compatibility of $\mathrm{CF} / \mathrm{PEEK}$ composite with $\mathrm{PEEK}-\mathrm{NH}_{2}$ was improved. However, the value of $\tan \delta$ was affected by the degree of amination due to the high sensitivity of $\mathrm{NH}_{2}$ due to high temperature.

A

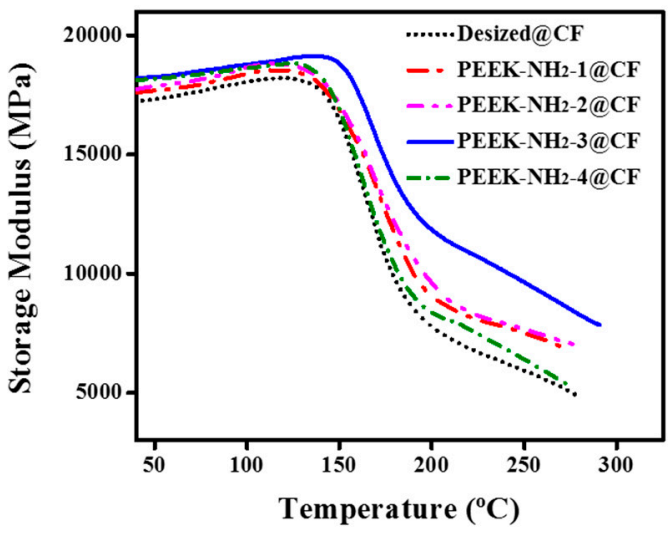

B

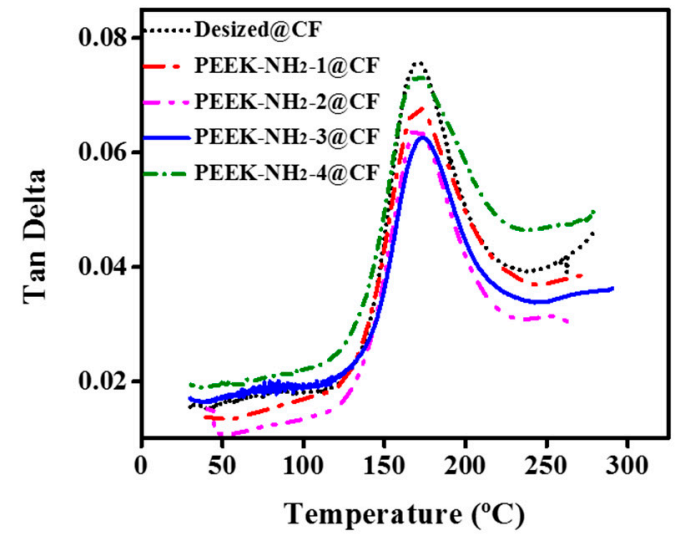

Figure 8. (A) Storage modulus and (B) $\tan \delta$ of PEEK-NH$H_{2}$ modified CF/PEEK composites. 


\subsection{The Fractured Surface of the Modified Composite}

The pulled out CF and the big crack in the interface of the desized CF/PEEK composite were observed (see arrows in Figure 9Ai,ii). As shown in Figure 9Aiii, the debonding failure surfaces presented a little matrix attached to the $\mathrm{CF}$ surface. These results indicated a poor interface between $\mathrm{CF}$ and PEEK. The surface morphologies of PEEK-NH $\mathrm{N}_{2}-1 @ \mathrm{CF}$ are shown in Figure 9Bi,ii. The pulled out CFs in the modified CF/PEEK composite were not observed but a small crack was deflected. As shown in Figure 9Biii, some PEEK resin detached from the CFs surface owing to the relatively weak adhesion between $\mathrm{CF}$ and PEEK resin. For PEEK-NH $\mathrm{N}_{2}-2 @ \mathrm{CF}$, the crack was reduced and there was no gap between $\mathrm{CF}$ and the matrix (Figure 9Ci,ii). Furthermore, as shown in Figure 9Ciii, more PEEK resin was attached in CFs compared with PEEK-NH $\mathrm{N}_{2}-1 @ \mathrm{CF}$, which indicated that the interface improved to some extent. For PEEK-NH $\mathrm{N}_{2}-3 @ \mathrm{CF}$, it suggested that the fiber was broken together with the matrix during the fracture, which further substantiates adhesion between PEEK and CF (Figure 9Di,ii). Besides; it is found that more resins completely adhered on the surface of PEEK-NH $\mathrm{N}_{2}-3 @ \mathrm{CF}$ (Figure 9Diii). It can be inferred that the interfacial properties of PEEK-NH $\mathrm{N}_{2}-3 @ \mathrm{CF}$ composites were improved with the increased degree of amination, which is in good agreement with previous experimental results of ILSS. The improvement can be attributed to the chemical bond between PEEK- $\mathrm{NH}_{2}$ and $\mathrm{COOH}$ in $\mathrm{CF}$, thus, building an interfacial layer on the surface of $\mathrm{CF}$ while improving wettability with the PEEK matrix. Meanwhile, the compatibilizer also had good compatibility with the PEEK matrix.

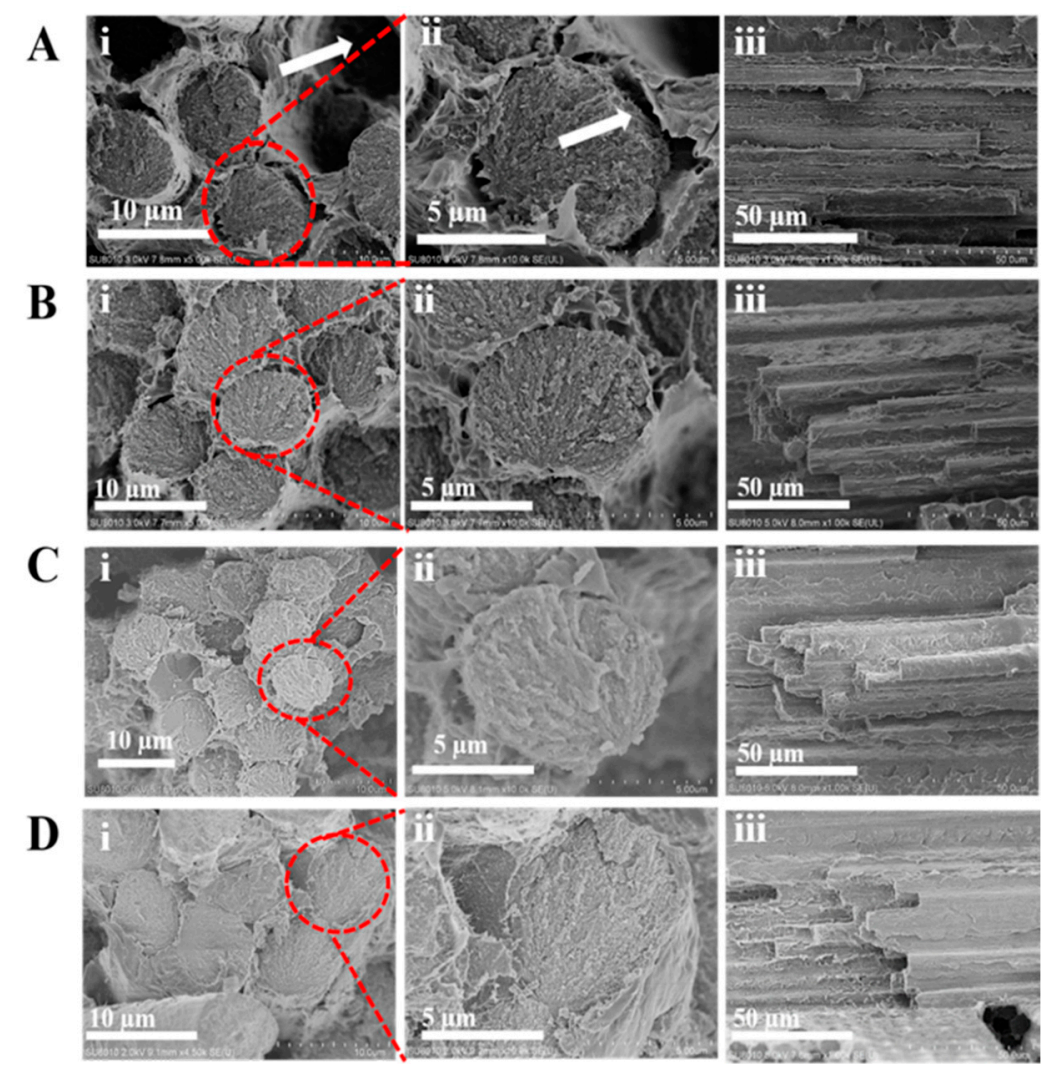

Figure 9. SEM images of fracture surface micrographs of CF-PEEK composites containing CF with different modifications: (A) Desized@CF, (B) PEEK-NH $\mathrm{H}_{2}-1 @ \mathrm{CF},(\mathrm{C}) \mathrm{PEEK}-\mathrm{NH}_{2}-2 @ \mathrm{CF}$, and (D) PEEK-NH2-3@CF.

\section{Conclusions}

In this work, a modified method based on the PEEK-NH $\mathrm{N}_{2}$ matrix was investigated. The PEEK-NH $\mathrm{NH}_{2}$ was grafted onto $\mathrm{CFs}$ via chemical bonding. Effective improvement in the interfacial adhesion could be achieved by forming a covalent bond between the amino group of PEEK and $\mathrm{COOH}$ of the 
activated CF. Although, PEEK-NH ${ }_{2}$ has good compatibility with PEEK, the study showed a limited influence on improving interfacial adhesion, i.e., $33.4 \%$ for ILSS, probably due to the high sensitivity of the amine group to high temperatures. Meanwhile, the compatibility effect of PEEK-NH $\mathrm{N}_{2}$ in the PEEK/CF composite was proved not only by the mechanical properties, but also by the storage modulus and SEM observation of modified composites, since the properties of the CF/PEEK interface were significantly enhanced. This approach may be applied to other thermoplastics that have lower processing temperature to enhance their performance.

Author Contributions: Conceptualization, E.A.M.H., M.Y. and S.Z.; methodology, E.A.M.H. and S.Z.; software, E.A.M.H.; validation, E.A.M.H., T.H.H.E. and H.M.; formal analysis, E.A.M.H. and S.Z.; investigation, E.A.M.H. and S.Z.; resources, M.Y. and S.Z.; data curation, E.A.M.H. and S.Z.; writing-original draft preparation, E.A.M.H.; writing-review and editing, T.H.H.E. and H.M.; visualization, E.A.M.H., M.Y. and S.Z.; supervision, M.Y. and S.Z.; project administration, S.Z.; funding acquisition, S.Z.

Funding: This research was funded by the Fundamental Research Funds for the Central Universities (No. 2232018D3-16), the Shanghai Science and Technology Committee Project (17511102801 and 16DZ112140) and the Base Project of Key Laboratory of High Performance Fibers and Products in Ministry of Education (2232019G-02).

Conflicts of Interest: The authors declare no conflict of interest.

\section{References}

1. Dworak, M.; Rudawski, A.; Markowski, J.; Blazewicz, S. Dynamic mechanical properties of carbon fibre-reinforced PEEK composites in simulated body-fluid. Compos. Struct. 2017, 161, 428-434. [CrossRef]

2. Hassan, E.A.M.; Ge, D.; Yang, L.; Zhou, J.; Liu, M.; Yu, M.; Zhu, S. Highly boosting the interlaminar shear strength of CF/PEEK composites via introduction of PEKK onto activated CF. Composites Part A 2018, 112, 155-160. [CrossRef]

3. Zou, H.; Yin, W.; Cai, C.; Wang, B.; Liu, A.; Yang, Z.; Li, Y.; He, X. The Out-of-Plane Compression Behavior of Cross-Ply AS4/PEEK Thermoplastic Composite Laminates at High Strain Rates. Materials 2018, 11, 2312. [CrossRef] [PubMed]

4. Gao, S.; Gao, S.; Xu, B.; Yu, H. Effects of Different pH-Values on the Nanomechanical Surface Properties of PEEK and CFR-PEEK Compared to Dental Resin-Based Materials. Materials 2015, 8, 4751. [CrossRef] [PubMed]

5. Pérez-Pacheco, E.; Moreno-Chulim, M.; Valadez-González, A.; Rios-Soberanis, C.; Herrera-Franco, P. Effect of the interphase microstructure on the behavior of carbon fiber/epoxy resin model composite in a thermal environment. J. Mater. Sci. 2011, 46, 4026-4033. [CrossRef]

6. Ma, R.; Tang, T. Current Strategies to Improve the Bioactivity of PEEK. Int. J. Mol. Sci. 2014, 15, 5426-5445. [CrossRef] [PubMed]

7. Diez-Pascual, A.M.; Martinez, G.; Gomez, M.A. Synthesis and characterization of poly (ether ether ketone) derivatives obtained by carbonyl reduction. Macromolecules 2009, 42, 6885-6892. [CrossRef]

8. Guo, H.; Huang, Y.; Meng, L.; Liu, L.; Fan, D.; Liu, D. Interface property of carbon fibers/epoxy resin composite improved by hydrogen peroxide in supercritical water. Mater. Lett. 2009, 63, 1531-1534. [CrossRef]

9. Vieille, B.; Casado, V.M.; Bouvet, C. About the impact behavior of woven-ply carbon fiber-reinforced thermoplastic-and thermosetting-composites: a comparative study. Compos. struct. 2013, 101, 9-21. [CrossRef]

10. Luo, H.; Xiong, G.; Yang, Z.; Raman, S.R.; Li, Q.; Ma, C.; Li, D.; Wang, Z.; Wan, Y. Preparation of three-dimensional braided carbon fiber-reinforced PEEK composites for potential load-bearing bone fixations. Part I. Mechanical properties and cytocompatibility. J. Mech. Behav. Biomed. Mater. 2014, 29, 103-113. [CrossRef] [PubMed]

11. Takei, H.; Salvia, M.; Vautrin, A.; Tonegawa, A.; Nishi, Y. Effects of Electron Beam Irradiation on Elasticity of CFRTP (CF/PEEK). Mater. Trans. 2011, 52, 734-739. [CrossRef]

12. Li, J. Interfacial studies on the ozone and air-oxidation-modified carbon fiber reinforced PEEK composites. Surf. Interface Anal. 2009, 41, 310-315. [CrossRef]

13. Jang, J.; Kim, H. Improvement of carbon fiber/PEEK hybrid fabric composites using plasma treatment. Polym. Compos. 1997, 18, 125-132. [CrossRef] 
14. Ashrafi, B.; Díez-Pascual, A.M.; Johnson, L.; Genest, M.; Hind, S.; Martinez-Rubi, Y.; González-Domínguez, J.M.; Martínez, M.T.; Simard, B.; Gómez-Fatou, M.A. Processing and properties of PEEK/glass fiber laminates: Effect of addition of single-walled carbon nanotubes. Compos. Part A Appl. Sci. Manuf. 2012, 43, 1267-1279. [CrossRef]

15. Pan, L.; Yapici, U. A comparative study on mechanical properties of carbon fiber/PEEK composites. Adv. Compos. Mater. 2016, 25, 359-374. [CrossRef]

16. Zhang, S.; Liu, W.; Wang, J.; Li, B.; Hao, L.; Wang, R. Improvement of interfacial properties of carbon fiber-reinforced poly (phthalazinone ether ketone) composites by introducing carbon nanotube to the interphase. Polym. Compos. 2015, 36, 26-33. [CrossRef]

17. Yuan, H.; Zhang, S.; Lu, C. Surface modification of carbon fibers by a polyether sulfone emulsion sizing for increased interfacial adhesion with polyether sulfone. Appl. Surf. Sci. 2014, 317, 737-744. [CrossRef]

18. Liu, W.; Zhang, S.; Hao, L.; Jiao, W.; Yang, F.; Li, X.; Wang, R. Properties of carbon fiber sized with poly (phthalazinone ether ketone) resin. J. Appl. Polym. Sci. 2013, 128, 3702-3709. [CrossRef]

19. Owens, D.K.; Wendt, R.C. Estimation of the surface free energy of polymers. J. Appl. Polym. Sci. 1969, 13, 1741-1747. [CrossRef]

20. Cuiqin, F.; Jinxian, W.; Julin, W.; Tao, Z. Modification of carbon fiber surfaces via grafting with Meldrum's acid. Appl. Surf. Sci. 2015, 356, 9-17. [CrossRef]

21. Conceição, T.F.; Bertolino, J.R.; Barra, G.M.; Mireski, S.L.; Joussef, A.C.; Pires, A.T. Preparation and characterization of poly (ether ether ketone) derivatives. J. Braz. Chem. Soc. 2008, 19, 111-116. [CrossRef]

22. Wang, D.; Zhang, X.; Nie, S.; Zhao, W.; Lu, Y.; Sun, S.; Zhao, C. Photoresponsive Surface Molecularly Imprinted Poly(ether sulfone) Microfibers. Langmuir 2012, 28, 13284-13293. [CrossRef] [PubMed]

23. Hu, H.; Zhang, T.; Yuan, S.; Tang, S. Functionalization of multi-walled carbon nanotubes with phenylenediamine for enhanced $\mathrm{CO}_{2}$ adsorption. Adsorption 2017, 23, 73-85. [CrossRef]

24. Wu, G.; Ma, L.; Liu, L.; Wang, Y.; Xie, F.; Zhong, Z.; Zhao, M.; Jiang, B.; Huang, Y. Interfacially reinforced methylphenylsilicone resin composites by chemically grafting multiwall carbon nanotubes onto carbon fibers. Composites Part B 2015, 82, 50-58. [CrossRef]

25. Su, Y.; Zhang, S.; Zhang, X.; Zhao, Z.; Chen, C.; Jing, D. Preparation and properties of graphene/carbon fiber/poly (ether ether ketone) composites. Carbon 2017, 124, 723.

26. Santos, A.L.; Botelho, E.C.; Kostov, K.G.; Ueda, M.; da Silva, L.L.G. Carbon fiber surface modification by plasma treatment for interface adhesion improvements of aerospace composites. Adv. Mater. Res. 2016, 1135, 75-87. [CrossRef]

(C) 2019 by the authors. Licensee MDPI, Basel, Switzerland. This article is an open access article distributed under the terms and conditions of the Creative Commons Attribution (CC BY) license (http://creativecommons.org/licenses/by/4.0/). 